would sometimes be an advantage to have one presenting a broader view and making no reference to any specific temperature, just as the ordinary definition of critical temperature makes no reference to any specific pressure.

Now, if in a $p v$ diagram we draw the curve formed by the liquid and vapour lines, the indicator points corresponding to the "mixed state" (i.e. part vapour and part liquid, each more or less distincily discernible) lie wholly within the region bounded by this curve and the axis of volume ; also the ordinate of the highest point of this curve-where, of course, the tangent is horizontal-corresponds to the critical pressure, and the "critopiestic" or critical pressure line is the said horizontal tangent.

All horizontal lines below the critopiestic intersect the region corresponding to the "mixed state," while those above do not, thus showing that at pressures below the critical the substance changes from gas to liquid, or vice-versa, by the ordinary process of condensation or evaporation, i.e. by passage through the mixed state, while above that pressure this process does not take place, but the change occurs by continuous and imperceptible transition.

Of course all this accords with experiment, as is pointed out in several, though by no means all, the standard text-books. Thus on p. I 23 of the new edition of Clerk Maxwell's " Theory of Heat," revised by Lord Rayleigh, we read :- " If we begin with carbonic acid gas at $50^{\circ} \mathrm{F}$. we may first heat it till its temperature is above the critical, $88^{\circ} \mathrm{F}$. We then gradually increase the pressure to, say, Ioo atmospheres. During this process no sign of liquefaction occurs. Finally we cool the substance still under a pressure of 100 atmospheres to $50^{\circ} \mathrm{F}$. During this process no sudden change of state can be observet, but carbonic acid at $50^{\circ} \mathrm{F}$. and under a pressure of 100 atmospheres has all the properties of a liquid . . . by this process we have caused the substance to pass from an undoubledly gaseous to an undoubtedly liquid state without at any time undergoing an abrupt change similar to ordinary liquefaction."

Again, on p. 206 of the "Text-Book of Physics," by Mr. Alfred Daniell, we find :- " If $\mathrm{CO}_{2}$ gas be exposed to a temperature above $30^{\circ} 92 \mathrm{C}$. and be subjected to any pressure above 73 atmospheres, it will still be a gas : allow it to cool, the pressure being kept up, and it will be a liquid after it passes $30^{\circ} .92 \mathrm{C}$., and yet the transition is unobservable."

I therefore propose to define the critical pressure of a sub. stance as "that pressure above which it is impossible to make the substance undergo the ordinary process of condensation (or evaporation)"--or if greater amplification is needed as "that pressure above which an appropriate alteration of temperature causes the substance to pass from the gaseous to the liquid state or vice-versa, by a process of continuous and imperceptible transition, and not, as happens below that pressure, by passage through the mixed state."

This definition I have given in my recently published book, "Physics : Experimental and Theoretical," but the Times reviewer, in a paragraph in that paper of July 29 , characterises it as "mere nonsense."

I shall be greatly obliged if you will publish this letter, together with your opinion on the validity of my definition. Perhaps also some of your readers may favour me with an expression ol their views.

Newcastle-upon-Tyne, August 2.

R. H. JUile.

\section{Maternal Devotion of Spiders.}

ON removing some virgin cork from the wall of a conservatory a short time ago, I was much struck with the way in which a small black female spider clung to her two egg-bags, despite the fact that the piece of cork to which she was clinging had been thrown roughly to the ground. When the cork was about to be replaced on the wall, it became necessary to turn the spicler adrift, in order to prevent her being crushed. But although the cork was shaken, she declined to budge, and retained a tight hold upon her precious bags. Knowing how fully alive to danger the spider race is in general, I thought that this remarkable instance of devotion to maternal promptings on the part of a naturally sensitive creature ought not to be disregarded. I accordingly removed the mother very care. fully, and placed her on some rockwork, where I noticed she seemed to be very uneasy, moving restlessly about as if searching for something. I then took the egg-bags and placed them beside her. As I expected, she seemingly failed to recognise them, or at least manifested a repugnance to them, and ran away for a little distance. Subsequently, however, she returned, and proceeded to examine the bags with scrupulous care by means of her palpi ; and evidently satisfied with this scrutiny that they were really her own cherished property, she commenced o spin a web about them to secure them in their place.

Rennie has described experiments with the females of certain spiders which carry about their egg-bags attached to their bodies. When one of these spiders was molested, and its bag dragged with a stick, the mother seemed to lose all sense of personal danger in her anxiety for her unhatched offspring, and fought vigorously to retain her precious egg-bag. When forcibly deprived of the bag, she manifested great distress, and commenced a search for it, and, not finding it, she refused to leave the spot, seeming to be quite indifferent as to her fate. The curious part of the story is that when the egg-bag was finally restored to her, she refused to touch it, being apparently quite unable to recognise her property. In another case the spider regained possession of the bag as it was being withdrawn, and immediately refixed it in its former position.

My spider apparently recognised her egg-bags without much difficulty, and, furthermore, seemed to be alive to the danger to which they were exposed in their new situation by her act of spinning a protecting web without delay. When evening arrived, I observed that she had drawn the bags close up under a sheltering leaf, and was guarding them closely, having placed herself between them. FRANCIS J. ROWBOTHAM.

August 23.

\section{THE CAMBRIDGE ANTHROPOLOGICAL EX \\ PEDITION TO TORRES STRAITS AND SARAWAK.}

THE main object of the expedition was to verify and supplement the anthropological observations that I made in Torres Straits in $1888-89$, with the view of the publication of a monograph dealing with the anthropology of the islanders using that term in its widest sense. A few months before leaving I received such a pressing and enthusiastic invitation from $\mathrm{Mr}$. Charles Hose for the expedition to visit the Baram district of Sarawak, that I felt constrained to extend the scope of our work by accepting his tempting offer. The party consisted of Dr. W. H. R. Rivers, Messrs. C. S. Myers, W. McDougall, S. H. Ray, A. Wilkin, C. G. Seligmann, and myself.

The Torres Straits islanders are Papuans, and as they inhabit the remains of the old land communication between Australia and New Guinea it was important that they should be thoroughly studied before it was too late. The islanders have been more or less under mission instruction since 1872 , and some time before then the pearl-shelling industry had commenced. Owing to the varied influences of the white man, modification was bound to take place rapidly, and unfortunately in most islands more or less extensive depopulation has also occurred. There are two distinct tribes in the archipelago - the eastern tribe inhabits the Murray Islands, Erub (Darnley Island) and Uga, and the western tribe the remaining islands. The latter people have been most under the influence of white men, scarcely a pure-blooded native exists in Erub, but the Murray Islands, on account of their remoteness and the difficulties in reaching them owing to numerous coral reefs, have been less visited. As Mer, the chief island of this group is very fertile, and has a population of some 450 people, it appeared to be the best centre for our work.

We reached Mer on May 6, 1898, and took possession of the disused mission residence, which we speedily converted into anthropological, psychological and photographic laboratories. Here we measured 63 men, 5 women, 30 boys, and 22 girls. The average height of the men is $1.653 \mathrm{~m}$. ( $5 \mathrm{ft} .5 \mathrm{in}$.) ; their cephalic index is 77.5 . Although reference is made here only to the cephalic index and the height, I may state that we usually made

$$
\text { NO. I } 557 \text {, VOL. 6o] }
$$


twenty-two measurements on the subjects in Torres Straits, New Guinea, and Borneo, besides a number of observations on the skin, hair, eyes, face, \&c.

Psychological observations were made in the Murray Islands on about 150 individuals. Among the subjects investigated were visual acuity, delicacy of colour sense, colour blindness, binocular vision and visual perception of space; acuity and range of hearing, appreciation of musical intervals ; tactile acuity and sensibility to pain, and discrimination of weight; acuity of smell; simple reaction time to auditory and visual stimuli and choice reaction time; estimation of intervals of time; the influence of various mental states on blood pressure ; and the influence of fatigue and practice on the capacity for mental work. By means of colour matches, quantitative records were also taken of the colour of the skin of the islanders.

We were fortunate to find two or three old men who were able to tell us about the old customs and ceremonies. A good deal of time was spent in elucidating the long since abandoned sacred Malu ceremonies which were held in connection with the initiation of the youths; the previous account ${ }^{1}$ can now be considerably augmented. Notes were made of various other ceremonies, and whenever possible the ancient sacred songs were recorded on the phonograph. A large collection was made of sacred stones, including stones about which there is a legend, sorcery stones, fishing and garden charms, rain and fire charms. Numerous legends were also collected, and many of the sites and stones connected with them were photographed by Mr. Wilkin.

The old oracle known as "Tomog zogo," which consisted of a group of large shells on stones, to represent each group of houses on the island, and a shell "house" for the zogo, was plotted, and the former method of divination was demonstrated to us. One or two members of the party learnt the constellations on the voyage out ; this enabled us to map some of the native star groups. Attention was also paid to children's games, and a system of romenclature was devised which enabled us to record with accuracy the complicated manipulation in the making of the ingenious string puzzles or "cat'scradle." Examples of the past and present handicrafts of the people were collected. The construction of the language was carefully studied by Mr. Ray, and the previously published vocabulary increased. The native diseases and their cures were studied with the cognate charms and magic.

Messrs. Ray, Seligmann, Wilkin and myself paid a brief visit to the mainland of New Guinea, and visits were paid to Rabao (Yule Island) and to several villages of the Mekeo district. Twenty-eight men were measured: average height, ${ }^{\circ} 610 \mathrm{~m}$. ( $5 \mathrm{ft}$. $3 \frac{1}{2} \mathrm{in}$.); cephalic index, 8o. As the decorative art of the Mekeo district has not been described hitherto, numerous specimens of lime-gourds, tobacco-pipes, and painted tapa were collected.

A short stay was made at Port Moresby, where a number of photographs were taken to illustrate the manufacture of pottery, and a visit was paid to the Taburi tribe that lives behind Mount Warirata. Nine mountaineers from the centre of the Peninsula were measured : height, $\mathrm{I} 607 \mathrm{~m}$. ( $5 \mathrm{ft} .3^{\frac{1}{4}} \mathrm{in}$.) ; cephalic index, 80.8 , as well as fourteen Koiari from the hilly country : height, $\mathrm{r} 600 \mathrm{~m}$. ( $5 \mathrm{ft} .3 \mathrm{in}$.); cephalic index, 75.5 ; and six Koitapu of Port Moresby : height, $1^{\circ} 603 \mathrm{~m}$. ( $5 \mathrm{ft} .3$ in.) ; cephalic index, $77^{\circ}$. A study of the Koitapu language was made, which proved that it, like the people themselves, does not belong to the Motu stock. These three groups differ in several respects from the Motu communities that inhabit most of the coast villages from Delena to Aroma; for example, they

1 Internationales Archiv fïr Ethnographie (vi., 1893, p. 140). NO. I 557 , voL. 6o] commonly wear hair on the face, and the hair is almost invariably frizzly.

A few days were spent at Bulaa (Hula), where we were struck by the relative prevalence of curly and even of wavy hair, and the general lighter colour of the skin: height, $\mathrm{I}^{\circ} 66_{3} \mathrm{~m}$. (5 ft. $5 \frac{1}{2}$ in.); cephalic index, 82.5 . I intend on a future occasion to discuss the physical characters of the Papuans at some length when I have had time to tabulate out our results, and to compare them with those of other workers. At present it appears to me that a short, slightly brachycephalic people live amony the mountains, and a similar short mesaticephalic (with a distinct tendency towards dolichocephalism) folk live nearer the coast. It is the latter people who have been repressed by the taller brachycephals of the coast, whose foreign blood is shown by their lighter skin and a marked frequency of curly or even wavy hair. The mountaineers are in no sense a pygmy people, and are not directly related to the Aëtas ; they frequently harass ànd conquer the dolichocephals.

Messrs. Ray, Wilkin and myself returned to Murray Island on July $20, \mathrm{Mr}$. Seligmann remaining behind to see more of the country. Dr. Rivers and Messrs. Myers and McDougall had made a large number of interesting psychological observations during our absence. The two latter left for Borneo on August 24.

On September 8 we left Murray Island and arrived at Saguane at the southern end of Kiwai Island in the delta of the Fly River on the IIth. A visit was paid to Iasa, which contains sixteen long houses, each of which is inhabited by members of one totemistic clan, and eleven natives were measured: height, $1.602 \mathrm{~m}$. (5 ft. 3 in); cephalic index, $80^{\circ} 3$. Mr. Seligmann rejoined us here.

Our next destination was Mabuiag, which we reached on September 17, and had five weeks of good work recording old customs, measuring natives, studying language and experimental psychology. In Mabuiag and Kiwai fewer psychological observations could be made, owing to the fact that most of the apparatus had to be taken on to Borneo, but observations on visual acuity, colour vision, \&c., were made on over roo individuals, many of whom, however, were not natives of these islands. Thirty-three men were measured: height, $\mathrm{I}^{\circ} 648 \mathrm{~m}$. ( $5 \mathrm{ft}$. $4 \frac{3}{4}$ in.); the average cephalic index is $8 \mathrm{r} \cdot \mathrm{r}$. Although they belong to the same race, and are similar in many respects, there is a noticeable difference between the eastern and western tribe of Torres Straits. Most of their former ceremories and many of their customs were dissimilar, the languages are quite distinct, and on the whole the western folk are more intelligent. The very slight difference in the stature may be due to the more abundant food of Murray Island, whereas that of the head form is of greater significance. The difference between an average index of 77 and 81 may not appear large, but there is a distinct difference in the form of the skulls in general from the two islands. I am inclined to believe that the Murray Islanders belong to that dolichocephalic stock which certainly occurs on the mainland of New Guinea in the region known under the general name of Daudai, and which appears to have been pushed back by a somewhat brachycephalic people. Murray Island was unaffected by this movement, but the western islands have not escaped it. I have no desire to push craniological facts too far, and I propose testing this hypothesis elsewhere by cultural evidence. Several writers have expressed an opinion that the natives of Prince of Wales Island and the neighbouring islands are Australians with a strong Yapuan mixture. I regard them as Papuans, with a very slight (if any) Australian mixture.

The most interesting of our sociological investigations of the Western tribe were those on totemism, maturity customs for men and women, and the beginnings of heroworship as exemplified in the legend and cult of Kwoiam, the national hero of Mabuiag. Here, as at Mer, Dr. 
Rivers traced as far as possible the genealogy and relationships of every person on the island. This somewhat laborious work has proved a most valuable method of anthropological research, which, so far as I am aware, has not been attempted before for a whole community. The value of this method consists in the large number of accurate sociological data that are accumulated.

Short visits were paid to other of the western islands of the Straits in which ethnographical facts and specimens were collected.

At Mabuiag, and later at Thursday Island, we had an opportunity of studying some North Queensland natives, and the contrast, both mentally and physically, between them and the islanders was obvious. The average height of seventeen Queenslanders was I $626 \mathrm{~m}$. (5 ft. 4 in.), and their average cephalic index was $74^{\circ} 5$.

We finally left Torres Straits on November I5, I 898.

Messrs. Ray, Seligmann and myself reached Kuching on December 12, where we had to remain until January 4 ; Mr. Ray occupied the time in learning Malay, and I laid the foundations of a study of the decorative art of Sarawak by utilising the collections in the most excellent museum which the Rajah has so wisely and liberally endowed. The foundation of the ethnographical collections was the very valuable Brooke Low collection, which the Rajah bought in England and reshipped to its native land. This has been added to from time to time, and, although there is a good deal to be done before all the handicrafts and arts of the natives of Sarawak are fully illustrated, the museum contains the best and most instructive collection of Sarawak ethnography extant. The fauna of Sarawak is also most fully represented, and the value of the collections is daily increased by the welldirected labours of the curator, Mr. R. Shelford.

During the north-east monsoon it is impossible for a steamer to cross the bar at Baram Mouth, and this necessitated our proceeding to Limbang, where we had to remain a few days whilst messengers were sent to $\mathrm{Mr}$. Hose. We then had to journey some 200 miles in boats up the Limbang, Madalam and Trikan rivers, and after walking across the watershed at the foot of Mount Mulu we descended the Malinau, Tutau and Baram, arriving at Marudi (Claudetown) on January 28, where we rejoined Mr. McDougall, Mr. Myers having been obliged to return home a few days previously. On February $6 \mathrm{Mr}$. Hose took Messrs. Ray, MacDougall and myself an up-river trip, Mr. Seligmann was busy studying upoh (upas), tuba and other poisons; later he stayed some time among the up river Kayans. We went over 200 miles up the rivers Baram, Tinjar, Dapoi and Lobong, and saw many interesting scenes, and gained further experience of the jungle vegetation of a typical tropical land.

At Long Puah we witnessed the ceremony of moving the skulls into a new house from the hut in which they had been temporarily lodged, and then we participated in the ceremony of naming the first-born son of the chief. On the same occasion peace was made between two hostile tribes, and the covenant was ratified in the usual manner by "speaking" to some pigs, that were then killed and their livers inspected for augury. In one village we saw a Punan medicine man exorcise fever from a white man by means of incantations and obvious thaumaturgics. We gained fair insight into the mode of life and beliefs of several tribes of the interior; we made collections to illustrate their handicrafts and decorative art; numerous photographs were taken, which unfortunately have not proved a success owing partly to climatic conditions. Physical measurements were made of a large number of natives, and vocabularies collected. We also had an excellent object-lesson in the paternal administration of native affairs that is the keynote of the Sarawak system of government.

It was on this trip that I discovered a stone imple- ment in a native house, close by the usual skulls and associated with other sacred objects. After great difficulty Mr. Hose succeeded in procuring it, and later he secured several other specimens of varied types. With the exception of a specimen in the museum at Oxford of a very different type from any we obtained, and one recently acquired by the Sarawak Museum, these are the only authentic stone implements known from Borneo. Mr. McDougall and I paid a hurried visit to Mount Dulit, but nothing of interest was collected.

Later on Mr. Hose took me to visit Tama Bulan, the great Kenyah Penghulu, who lives on the Pata River. Messrs. Myers and McDougall had previously visited him.

Towards the end of our stay in Baram we were present at a great peace-making, when quite 6000 natives assembled from all parts of the Baram district, and even from beyond its borders. We thus had an unique opportunity of seeing representatives of nearly every important tribe of the Raj. Amongst other incidents we witnessed a canoe race in which about one thousand men competed, and participated in an attempt to tuba-poison a large lake in which over two thousand men wer engaged.

We have now in Cambridge specimens to fairly well illustrate the arts and crafts of the natives of Sarawak. Mr. Ray obtained material for grammars of the two dialects spoken respectively by the Land Dayaks and by the Sea Dayaks, as well as notes upon several other languages. Vocabularies of over 200 words were obtained in forty-six dialects spoken by various tribes of Sarawak. Mr. Myers made numerous psychological observations. Mr. Seligmann studied native medicine, \&c. Mr. McDougall paid special attention to the question of the relations of men to animals and plants in Borneo, and helped me with the measurements and physical observations of the natives. In all we measured some 276 natives, the bulk of whom are mesaticephalic or slightly brachycephalic. The following are some of the approximate average indices (the numbers in brackets refer to the number of each tribe that were measured) :Maloh (7)-probably an immigrant people from Java-76 ; Barawan (17), 77.5 ; Kalabit (10), 78 ; Kenyah (103), 79 --of these the Sibops (5) have the lowest index with $75^{\circ}$, which gradually rises through the Malangs (20), 76.5 , Tabalos (3), 77.5, Madangs (6), 78, Long Pokun (19) and Lirong (15), 79.5, Long Dallo (12), 80.5, Apoh (9), 82, to the Long Sinong Kenyahs (5), with an index of $83^{\prime} 5^{-}$-this does not appear to be a very homogeneous group; Kayan (22), 80; Long Kiput (9), 80.5 ; Punan (22), 81 ; Sea Dayaks (53), 83; Malanaus (7), 85.5; Brunei-Malay (I), 85.5 . We have not yet had time to study the skulls we brought away. I had an opportunity, however, of measuring five Murut skulls at Limbang, which had an average index of $75^{\circ}$ (extremes $73^{-77} 7^{\circ}$ ) It is thus evident that there is a dolichocephalic element in Borneo which may be identical with the Indonesians as defined by de Quatrefages and Hamy in "Crania Ethnica." There is also a low brachycephalic element found among the up-river Kenyahs (Long Sinong, Apoh, and Long Dallo), Punans, and to a less extent among the Kayans. The Sea Dayaks are not an indigenous population ; they probably constituted the advance wave of a later Malay migration. The Malanaus are Mohammedans greatly influenced by Malays, and who very frequently artificially deform the heads of their babies, so their relatively high index of 85.5 may be neglected. Although the Punan cephalic index $(8 I)$ is close to that of the Sea Dayaks (83), the slender pale-coloured forestdweller is physically very different from the short, sturdy, dark-skinned, low-country agriculturist. We were fortunate in coming across several groups of Punans, a nomadic jungle folk who are certainly one of the most primitive people in Borneo, and who may, perhaps, be the true autocthones of the country, for there is no

NO. 1557 , VOL. 6o] 
authoritative evidence for the existence of Negritos in Borneo.

The fascinating promises of $\mathrm{Mr}$. Hose when he sent me his invitation to visit him were amply fulfilled so far as time permitted, and we have to thank him for a most enjoyable and instructive visit. Mr. Charles Hose is well known as a highly successful and enthusiastic naturalist. He has made collections in all departments of the land fauna of Sarawak, and he has monographed the mammals and the birds. His geographical explorations are also well recognised; but it is not generally known that he has a most minute and extensive knowledge of all that pertains to the numerous and varied natives that have been entrusted to his sympathetic care. I have seen piles of immensely valuable ethnographical manuscript which we sincerely hope will be suitably and speedily published. Not only has Mr. Hose from time to time presented his old University with numerous zoological specimens, but he has entrusted to me an extensive and very valuable collection of ethnographic specimens which he has given to the University of Cambridge. In addition he has presented the unique collection of stone implements and a large collection of human crania, each skull being labelled with its tribe and provenance.

I shall endeavour on another occasion to do justice to Mr. Hose's success as an administrator. What we were able to accomplish was largely due to those personal qualities of a ruler which awaken a feeling of affection and loyalty in the natives.

The Cambridge University Press will publish the scientific results of the Expedition in due course as a series of memoirs which will be obtainable separately. The volume on experimental psychology will be written by Dr. Rivers and Messrs. Myers and McDougall, with some supplementary observations on the natives of the mainland of New Guinea by Mr. Seligmann. Mr. Ray has ample matter for a volume on linguistics.

The linguistic results of the Expedition were on the whole very satisfactory. Materials were obtained for complete grammars of the two Torres Straits languages, and the vocabularies were revised. In New Guinea the Melanesian languages around Hood Bay were studied, as well as those of Rabao (Yule Island) and the adjacent mainland. In New Guinea also material was obtained to elucidate the somewhat complex structure of the Papuan languages of the Koitapu in the Port Moresby district, of the Cloudy Bay peoples, and of the Kiwai and Mowatta tribes in the Fly Delta. No grammar of any of these languages has hitherto been written. The materials obtained in Borneo for grammars of the two dialects spoken by the Land Dayaks and Sea Dayaks, and vocabularies obtained in forty-six dialects spoken by various tribes of Sarawak have already been referred to.

The physical anthropology of Torres Straits and New Guinea will mainly be worked out by myself, but Mr. Seligmann has some additional measurements from the mainland of New Guinea. Dr. Rivers will publish and expound his statistical inquiries. Mr. Myers is making a comparative study of native music. Mr. Seligmann has studied native medicines and charms, and has made various ethnological observations of some interest. Mr. Wilkin has made notes on native houses in New Guinea. The religious ceremonies, legends, and general ethnology will be treated by various members of the Expedition. Mr. Wilkin took a large number of excellent photographs in Torres Straits and New Guinea, which will be drawn upon for illustrative purposes. As there is no room for them in the present Museum of Archeology and Ethnology, the extensive collections are deposited temporarily in a couple of small houses in Cambridge, where, unfortunately, they run risk of deterioration.

AlFRED C. HADDON.
WHY PEOPLE GO TO SPAS.

$A$ NY observer who has the curiosity to pass in review the modern methods of medical treatment cannot fail to be struck by the increasing amount of attention which is being paid at the present time, both by the laity and the profession, to the spa treatment of disease. The fact that many thousands of patients flock annually to the different health resorts to seek relief from their ills, and the idea which prevails among a large section of the educated public, chiefly the well-to-do classes, that their existence is not complete without a yearly visit to one or other of the many spas, either at home or abroad, and that for their bodily well-being an annual "cure" is necessary, are phenomena which call for comment and demand explanation. The practice is by no means of recent growth, for it finds its origin in the almost universal belief, prevalent in ancient times, in the efficacy of natural mineral waters and baths in the cure of disease. Many instances of this might be quoted. The waters of Spa in Belgium were celebrated in the time of Livy ; the Romans built Bath in England, and fully recognised the value of its springs ; and they in turn derived their fondness for bathing from the Greeks. There is not wanting evidence to show that more ancient civilisations appreciated in a rude way the benefits to be obtained in this direction from the resources of nature. Throughout the middle ages the same belief was held, and many were the pilgrimages to the various springs then known. In the present day the same idea, shorn of much of the superstition that formerly clung to it, still prevails, and each watering place claims annually its numerous devotees. Not only among the laity is the assurance of the therapeutic value of natural mineral waters and baths firmly rooted, though doubtless there still remains a substratum of lingering superstition as a part foundation of that assurance, but also by the medical fraternity their utility is accepted, as is witnessed by the freedom with which their patients are sent to take the waters of this or that spring. In the minds of the latter, however, superstition has been replaced by knowledge, and they are well assured that such treatment has a definite and real value.

It becomes, then, a matter of interest to seek answers to the following questions: Whether, in the light of modern knowledge and research there is a solid foundation in fact for the faith that is placed by patients and their doctors in the utility of bathing and water-drinking; whether such measures possess any advantages over treatment by ordinary medicinal means; whether the lines of treatment followed at spas cannot be carried out equally well at the patient's home, and the necessity for a perhaps inconvenient visit to a watering place thereby be obviated; and, lastly, whether equal facilities for such treatment, and results equally good, are not obtainable in this country as at similar places on the continent?

$\mathrm{Up}$ to comparatively recent times the use of waters and baths in the cure of disease was purely empirical. Through long experience and repeated trial it came gradually to be ascertained that certain waters were beneficial in certain cases, and certain kinds of baths produced certain effects; wherefrom was elaborated a system of spa treatment on more or less rule of thumb principles. The exact nature of the action of these agents, the physiological effects they produced and the pathological conditions they influenced were ill-understood; the rationale, in short, of the treatment was wanting. Of late years, however, a large amount of sound scientific work has been done in this department of medicine. The action of mineral waters and baths has been made the subject of definite experiment and the results obtained applied to the perfection and extension of the methods; and thereby this branch of therapeutics, which 